\title{
Longitudinal Study on Mutation Profiles of Core Promoter and Precore Regions of the Hepatitis B Virus Genome in Children
}

\author{
YEN-HSUAN NI, MEI-HWEI CHANG, HONG-YUAN HSU, AND DAW-JEN TSUEI \\ Department of Pediatrics, National Taiwan University Hospital and National Taiwan University College \\ of Medicine
}

\begin{abstract}
ABST
Precore nucleotide 1896 and core promoter mutations may
account for hepatitis B e antigen (HBeAg) seroconversion in
chronic hepatitis B virus (HBV) infection, yet the mutational
profiles of the core promoter are largely unknown in children. An
age-matched, case-control study enrolled 110 chronic HBV-
infected children, including 55 HBeAg seroconverters and 55
nonseroconverters. Precore and core promoter genes of HBV
were sequenced and the serum viral genomes were genotyped
from three serial serum samples of the seroconverters and from
one serum sample of the nonseroconverters. Higher frequency of
A1775G and G1799C mutation rates and lower frequency of
A1752G mutation rate were found in the seroconverters. Precore
1896 mutation appeared more in seroconverters than in nonse-
roconverters (45.5\% versus $10.9 \%$; $p<0.001) .1762+1764$
mutation rates were not different between the seroconverters
(9.1\%) and the nonseroconverters $(5.5 \%)$. Genotype B was the
\end{abstract}
Hepatitis B e antigen ( $\mathrm{HBeAg})$, coded by the precore and core genes, is an important infectivity marker in hepatitis B virus (HBV) infection. $\mathrm{HBeAg}$ has been suggested to be a target of host cytotoxic $\mathrm{T}$ cell, and its disappearance may suggest an immune clearance of HBV (1). Seroconversion from $\mathrm{HBeAg}$ antigenemia to anti-HBe may occur spontaneously in the natural course of chronic HBV infection. This process usually suggests that HBV breaks through the immune tolerance and enters into a low replication phase (2). The factors that affect the rate of $\mathrm{HBeAg}$ seroconversion, including the age of the patients and maternal hepatitis B markers, were identified in our previous study (3). The G to A transition at nucleotide position 1896 (nucleotide position according to EcoRI site) was thought previously to be associated with $\mathrm{HBeAg}$ seroconversion. This mutation results in a stop codon

Received January 28, 2003; Accepted September 5, 2003.

Correspondence: Mei-Hwei Chang, M.D., Department of Pediatrics, National Taiwan University Hospital, 7 Chung-Shan South Road, Taipei, Taiwan 100; E-mail: mhchang@ha.mc.ntu.edu.tw

This study was supported by a grant from the National Science Council, Executive Yuan, Taiwan (NSC-86-2314-B-002-128).

DOI: 10.1203/01.PDR.0000136282.20470.87 major type. Genotype $\mathrm{C}$ was associated with core promoter 1762 +1764 mutations in the seroconverter group $(p=0.023)$. The conclusions of this study include the following: 1) mutations of core promoter at nucleotide position 1752, 1775, and 1799 have significant correlations with $\mathrm{HBeAg}$ seroconversion; 2) core promoter $1762+1764$ mutations play a minimal role in $\mathrm{HBeAg}$ seroconversion; 3) precore 1896 mutant accounted for half of childhood HBeAg seroconversion; 4) genotype $\mathrm{C}$ is associated with $1762+1764$ mutations during the process of $\mathrm{HBeAg}$ seroconversion. (Pediatr Res 56: 396-399, 2004)
Abbreviation
HBeAg, hepatitis B e antigen
HBV, hepatitis B virus
HBsAg, hepatitis B surface antigen

for the precore open reading frame (4) and was suggested to induce $\mathrm{HBeAg}$ loss and promote $\mathrm{HBeAg}$ seroconversion $(5,6)$. However, this mutation does not exist in every case of $\mathrm{HBeAg}$ seroconversion $(7,8)$.

Our previous long-term follow-up pediatric study revealed that the 1896 mutant and wild types could coexist before and after HBeAg seroconversion. Approximately half of the carrier children had no such mutant throughout the HBeAg seroconversion process (9). Some mechanisms other than 1896 precore mutant might account for $\mathrm{HBeAg}$ seroconversion.

Core promoter mutations, particularly an A to T mutation at 1762 and a $\mathrm{G}$ to $\mathrm{A}$ mutation at 1764 nucleotide position (1762 +1764 mutations), have drawn much attention in the mechanism of HBeAg seroconversion in adults (10). Core promoter has been mapped to the nucleotide position 1744-1851 and regulates the transcription of both precore and core RNAs (11). Core promoter mutations may reduce precore transcription (12), thus leading to the loss of serum HBeAg and resulting in $\mathrm{HBeAg}$ seroconversion (13).

Little is known about these mutations in children (14). Previous studies were generally small in scale and lacked a 
control group; thus, we do not know the background information of these mutants (15). Age is a known important factor for $\mathrm{HBeAg}$ seroconversion (3). We thus performed a large-scale, case-control, and age-matched study to minimize this factor and focus on clarifying the role of core promoter mutations in children.

\section{METHODS}

Subjects. A total of 415 children with chronic HBV infection were followed-up prospectively every 6 mo at our outpatient clinic with their parents' consent. Among the 415 children, 169 had already undergone HBeAg seroconversion. $\mathrm{HBeAg}$ seroconversion was defined as the conversion from $\mathrm{HBeAg}$ seropositive to anti-HBe positive at two different time points. The timing of $\mathrm{HBeAg}$ seroconversion was arbitrarily assigned to be the midpoint between these two different time points. Among the aforementioned 169 subjects, 55 children $(\mathrm{M}: \mathrm{F}=34: 21)$ were documented to undergo HBeAg seroconversion during follow-up and were followed up $\geq 2 \mathrm{y}$ after $\mathrm{HBeAg}$ seroconversion. They were also free from other concurrent medical illness. They thus were enrolled as the subjects of this study. All of these 55 children were asymptomatic clinically. Their mean age at enrollment was $6.1 \pm 4.6 \mathrm{y}, 11.2$ \pm 4.1 y (mean \pm SD; range: $3.7-23.5$ y) at HBeAg seroconversion, and $16.4 \pm 5.8 \mathrm{y}(5.6-32.0 \mathrm{y})$ at the last follow-up. For each case in this group, three blood samples were subjected to study: the first one was taken $<6$ mo before $\mathrm{HBeAg}$ seroconversion, the second one was within 6 mo after $\mathrm{HBeAg}$ seroconversion, and the latest available one was an average 5.2 $\pm 3.5 \mathrm{y}$ after $\mathrm{HBeAg}$ seroconversion. Maternal HBsAg was positive in 34 cases, negative in 20 cases, and unknown in 1 case.

Another $55 \mathrm{HBsAg}$ carrier children with persistent $\mathrm{HBeAg}$ antigenemia formed the control group. The subjects of the control group were selected on the basis of their age and sex. Their mean age at enrollment was $5.5 \pm 4.2 \mathrm{y}$, and the age at the latest check-up was $12.0 \pm 3.7$ y (2.6-21.6 y). The latter was matched with the seroconverters' age at seroconversion. The control group also has the same sex distribution as the study group. The presumed mode of acquisition was also matched (maternal HBsAg positive in 39 cases, negative in 14 cases, and unknown in 1 case). Their latest available serum samples were analyzed in this study. All 55 children were asymptomatic clinically, too.

All subjects were not treated with interferon or other antiviral agent during the study period. None of them had coexisting infection of hepatitis C or hepatitis D or HIV.

Serum hepatitis B markers and biochemical test. Hepatitis B surface antigen (HBsAg), anti-HBs, $\mathrm{HBeAg}$, anti-HBe, and anti-HBc were tested by RIA kit (Abbott, Abbott Park, IL, U.S.A.). The liver function profile was determined by an autoanalyzer (Hitachi 736, Tokyo, Japan).

Nested PCR to amplify the core promoter region of $\mathrm{HBV}$ genome. DNA was extracted from $20 \mu \mathrm{L}$ of serum by the standard SDS-proteinase $\mathrm{K} / \mathrm{phenol} / \mathrm{chloroform}$ method. The extracted DNA was then subjected to PCR as the template. Nested PCR was performed using the primers and procedures previously described (16). The sensitivity of our nested PCR was $10^{-5} \mathrm{pg}$ of HBV DNA. Strict rules were followed to avoid PCR contamination (17).

Sequencing of PCR products. Cyclic sequencing was performed using ABI prism dye-labeled terminators and cycle sequencing ready reaction kit. The procedure was done mainly according to the manufacturer's instructions (Perkin Elmer, Foster City, CA, U.S.A.). Briefly, dye terminator, dNTP, Tris$\mathrm{HCl}$ (pH 9.0), $\mathrm{MgCl}_{2}$, thermal stable pyrophosphatase, AmpliTaq DNA polymerase, and M13 primer $(0.8 \mathrm{pmol} / \mathrm{L})$ mixed with $2 \mu \mathrm{L}$ of template $(0.2 \mu \mathrm{g} / \mu \mathrm{L})$, and distilled water mixed to a total of $20 \mu \mathrm{L}$. The mixture was then processed to the reaction in GeneAmp PCR system 2400 (Perkin Elmer), after which it was loaded and read by the sequencer. For preventing the artifacts of point mutations created by PCR, the sequencing reactions were done in both directions. All of the tests were duplicated to confirm the results. The entire study protocol was approved by the National Science Council, Taiwan.

Determination of HBV genotypes by nested PCR. All of the serum samples were checked for HBV genotypes. The genotype analysis strategy was to adapt the method of PCR using type-specific primers (18). When the results were not interpretable after double check, we applied the restriction fragment length polymorphism method developed by Lindh et al. (19). The nested PCR sensitivity was $10^{-5} \mathrm{pg}$ of HBV DNA. All experiments were done at least in duplicate to confirm the results.

\section{RESULTS}

Clinical outcome. For the HBeAg seroconverter group, 47 of 55 had abnormal ALT changes (normal range of ALT $<40$ $\mathrm{U} / \mathrm{L}$ ) in the process of $\mathrm{HBeAg}$ seroconversion. Conversely, 3 of 55 of the subjects in the nonseroconverter group had abnormal ALT. Peak ALT levels, which were the highest ALT levels during the follow-up, were different between the two groups (median peak ALT levels of seroconverter group versus nonseroconverter group: 77, range 1-253 U/L versus 9, range $2-150 \mathrm{U} / \mathrm{L} ; p<0.0001$, Mann Whitney $U$ test). When we compared the ALT of the postseroconversion serum sample (the third serum sample) of the seroconverter group with that of the nonseroconverter group, there was no difference (median ALT of the third serum sample of seroconverter group versus nonseroconverter group: 9, range 2-109 U/L versus 9, range $2-150 \mathrm{U} / \mathrm{L} ; p<0.001$, Mann Whitney $U$ test). Only two cases with ALT higher than $1.5 \times$ upper normal limit $(>60 \mathrm{U} / \mathrm{L})$ were found in the third serum samples. Both bore no core gene mutations.

DNA sequence variations of the core promoter region and precore region. Nucleotide positions $1804-1845$ were a relatively conserved region with no mutation found. Core promoter nucleotide positions 1752, 1775, and 1799 had significantly different mutation rates between the seroconverters and nonseroconverters after HBeAg seroconversion (Table 1).

When we considered the presence of G1896A mutation in any one of the three serum samples of the seroconverter group, we found this mutation appeared in $25(45.5 \%)$ of 55 of the seroconverters during the follow-up course, whereas 6 of them 
Table 1. Mutation at HBV core promoter and precore regions in HBeAg seroconverter and non-seroconverter groups

\begin{tabular}{|c|c|c|c|c|c|}
\hline \multirow[b]{2}{*}{ Nucleotide } & \multirow[b]{2}{*}{ Mutation } & \multirow[b]{2}{*}{ Nonseroconverters } & \multicolumn{3}{|c|}{ Seroconverters } \\
\hline & & & First & Second & Third \\
\hline 1752 & $\mathrm{~A} \rightarrow \mathrm{G}$ & $36.4 \%$ & $25.5 \%$ & $7.3 \% *$ & $1.8 \% *$ \\
\hline 1773 & $\mathrm{C} \rightarrow \mathrm{T}$ & $3.6 \%$ & $10.9 \%$ & $14.6 \%$ & $12.7 \%$ \\
\hline 1775 & $\mathrm{~A} \rightarrow \mathrm{G}$ & $3.6 \%$ & $1.8 \%$ & $9.1 \%$ & $32.7 \% *$ \\
\hline 1799 & $\mathrm{G} \rightarrow \mathrm{C}$ & $29.1 \%$ & $29.1 \%$ & $65.5 \% *$ & $81.8 \% *$ \\
\hline 1850 & $\mathrm{~T} \rightarrow \mathrm{A}$ & $3.6 \%$ & $9.1 \%$ & $12.7 \%$ & $18.2 \%$ \\
\hline 1896 & $\mathrm{G} \rightarrow \mathrm{A}$ & $9.1 \%$ & $25.5 \% *$ & $29.1 \% *$ & $34.5 \% *$ \\
\hline
\end{tabular}

For each case in the HBeAg seroconverted group, three blood samples were subjected to study: the first one was taken before HBeAg seroconversion $(<6$ mo), the second was after HBeAg seroconversion ( $>6 \mathrm{mo}$ ), and the latest available one averaged $5.2 \pm 3.5 \mathrm{y}$ after HBeAg seroconversion. The first blood samples (before seroconversion) were compared with the nonseroconverted group, whereas the second and third blood samples (after seroconversion) were compared with the first blood samples.

$* p<0.05$ (Fisher's exact test or $\chi^{2}$ test with Yate's correction).

had this mutant reverted back to the wild type in the third serum sample. AG1762/1764TA was found in $6(10.9 \%)$ of 55 of the seroconverters in any of the three serum samples, whereas 1 of them had this mutant reverted back to the wild type in the third serum sample.

Mutations of core promoter and precore region other than 1896 and $1762+1764$ could be found in $19(34.5 \%)$ of 55 of the seroconverter group. Only five $(9 \%)$ in this group had neither precore G1896A mutation nor core promoter mutations in this study.

Only a minority of the nonseroconverters were with $\mathrm{C} 1858$ (3.6\%; 2 of 55 ), whereas $32.7 \%$ (18 of 55) of the seroconverters were found to have $\mathrm{C} 1858(p<0.001)$. Core promoter mutations of $1762+1764$ did not correlate with C1858. All children with 1896 precore stop codon mutation were exclusively infected with T1858 HBV.

Genotype and precore and core promoter mutations. In the seroconverter group, 25 cases were ever associated with precore 1896 mutation; 21 were genotype $\mathrm{B}$, and 4 were genotype $\mathrm{C}$, whereas for the 30 cases without this mutation, 26 were genotype $\mathrm{B}$ and 4 were genotype $\mathrm{C}$. The genotype distribution pattern is not different between those with and without precore 1896 mutation ( $p=0.78$, Fisher's exact test). Seven cases had core promoter $1762+1764$ mutations (genotype B:genotype C $=4: 3$ ). Compared with the other 41 cases without such mutations in the seroconverters (genotype B:genotype $\mathrm{C}=$ 43:5), genotype $C$ had a significantly higher association with core promoter $1762+1764$ mutations $(p=0.023)$.

The nonseroconverter group consisted of only five cases with precore 1896 mutation and four were genotype B and 1 was genotype $\mathrm{C}$, also not different from the data of those without precore 1896 mutation ( $4: 1$ versus $40: 10 ; p=1)$. Even fewer cases were associated with core promoter $1762+1764$ mutations: two were genotype B and one was genotype C. It was also not significantly different from those without core promoter $1762+1764$ mutation $(2: 1$ versus $42: 10 ; p=0.55)$.

\section{DISCUSSION}

This study provides a good chance to focus on the viral mutation impacts in the event of $\mathrm{HBeAg}$ seroconversion. Pre- core 1896 mutation was proposed to be one of the mechanisms to explain $\mathrm{HBeAg}$ seroconversion in the natural history of chronic HBV infection. However, there were still a proportion of patients who underwent $\mathrm{HBeAg}$ seroconversion without this mutation. In this study, we showed that 1896 mutations did appear more in the seroconverters. This precore mutation accounts for approximately half of the HBeAg seroconversions. Core promoter $1762+1764$ mutations were reported to be associated with chronic hepatitis and may be a possible mechanism for HBeAg clearance in adults (20), because the mutations negate $\mathrm{HBeAg}$ expression and lead to $\mathrm{HBeAg}$ seroconversion. However, the data in this study showed that the mutation profile of $1762+1764$ before seroconversion in the seroconverters was as low as in the nonseroconverters. This may suggest a minimal role of $1762+1764$ mutations in childhood $\mathrm{HBeAg}$ seroconversion. However, we found that genotype $\mathrm{C}$ had an association with the core promoter mutation in this childhood study. This finding is similar to the adult study (21).

In this study, we demonstrated that the percentage of patients with core promoter mutations in A1752G, A1775G, and G1799C are statistically different before and after $\mathrm{HBeAg}$ seroconversion. The proportions of mutant virions in each child before and after $\mathrm{HBeAg}$ seroconversion are not known in this study. However, our previous study and a recent study had demonstrated that virions of precore and core promoter mutants gradually increased in the transition of $\mathrm{HBeAg}$ seroconversion $(9,22)$.

It is interesting that the $\mathrm{A} 1752 \mathrm{G}$ mutation was found to appear more in the nonseroconverters and in the preseroconversion phase of the seroconverters. Nucleotide position 1752 is located in the Sp1 binding site of the core promoter (23). It may affect the transcription of precore RNA and reduce $\mathrm{HBeAg}$ production, thus relating to seroconversion. After $\mathrm{HBeAg}$ seroconversion, the mutants of $\mathrm{A} 1752 \mathrm{G}$ were largely cleared away. A1775G and G1799C mutations were demonstrated in the sequence analysis of genotype B (24). As shown in the current study, genotype B is the most prevalent HBV genotype in Taiwan, either in children or in adults (25). Thus, the appearance of these mutations could be expected. 
When we tally all of those with precore 1896 and/or core promoter mutations (Table 1), 91\% of these chronic HBVinfected children had mutations in these regions during the seroconversion process. Only $9 \%$ of them underwent $\mathrm{HBeAg}$ seroconversion without any mutations in the precore and core promoter regions in this study. This finding suggests the important role of these regions in $\mathrm{HBeAg}$ seroconversion.

The nucleotide 1858 of the precore gene is closely related to the evolution of G-1896 to A-1896 mutation to form a stop codon. This is because U1858 (T1858 in DNA) can form a base pair with G- and A-1896. HBV genotypes A and F are well correlated with HBV C1858, whereas HBV genotypes B, D, and E are well correlated with HBV T1858 (19). In our study, T1858 was the major type and C1858 was the minor type in either seroconverters or nonseroconverters with different frequency. C1858 was found in $3.6 \%$ of the nonseroconverter group and $32.7 \%$ of the seroconverter group, respectively. The higher rate of $\mathrm{C} 1858$ in the seroconverter group is different from that reported in adults (26). That the precore 1896 mutation was found exclusively in those with T1858 in this study is compatible with the previous report. However, C1858 was not associated with the core promoter $1762+1764$ mutation in this study.

For chronic HBV-infected children in Taiwan, we conclude that 1) mutations of core promoter nucleotide positions 1752 , 1775, and 1799 associate with HBeAg seroconversion; 2) 1762 +1764 mutations play a minimal role in HBeAg seroconversion in children; 3) more seroconverters had C1858 than the nonseroconverters, and $\mathrm{C} 1858$ tends to promote $\mathrm{HBeAg}$ seroconversion; and 4) precore 1896 mutant may account for $45 \%$ of childhood $\mathrm{HBeAg}$ seroconversion.

Acknowledgments. We acknowledge the technical assistance of Yi-Hsiung Chen and Yi Lin for DNA sequencing and laboratory data collection. We thank Su-Main Huang and Hsiu-Ping Huang for help in patient follow-up.

\section{REFERENCES}

1. Milich DR, Jones JE, Hughes JL, Price J, Raney AK, McLachlan A 1990 Is a function of the secreted hepatitis B e antigen to induce immunologic tolerance in utero? Proc Natl Acad Sci USA 87:6599-6603

2. Lee PI, Chang MH, Lee CY, Hsu HY, Chen PJ, Chen DS 1990 Changes of serum hepatitis B virus DNA and transaminase level in the natural course of chronic hepatitis B virus infection in children. Hepatology 12:657-660

3. Chang MH, Sung JL, Lee CY, Chen JS, Hsu HY, Lee PI, Chen DS 1989 Factors affecting the clearance of hepatitis B e antigen in hepatitis surface antigen carrier children. J Pediatr 115:385-390
4. Carman WF, Ferao M, Lok AS, Ma OC, Lai CL, Thomas HC 1992 Precore sequence variation in Chinese isolates of hepatitis B virus. J Infect Dis 165:127-133

5. Takeda K, Akahane Y, Suzuki H, Okamoto H, Tsuda F, Miyakawa Y, Mayumi M 1990 Defects in the precore region of the HBV genome in patients with chronic hepatitis B after sustained seroconversion from $\mathrm{HBeAg}$ to anti-HBe induced spontaneously or with interferon therapy. Hepatology 12:1284-1289

6. Feitelson M 1994 Biology of hepatitis B virus variants. Lab Invest 71:324-349

7. Nguyen XT, Fukuda R, Fukumoto S 1994 Precore region mutation in hepatitis B virus genome in early stage of infection: a study in hepatitis B e antigen-positive young carriers. J Gastroenterol 29:469-473

8. Bortolotti F, Crivellaro C, Brunetto MR, Cadrobbi P, Bertolini A, Alberti A 1993 Selection of a precore mutant of hepatitis $B$ virus and reactivation of chronic hepatitis $\mathrm{B}$ acquired in childhood. J Pediatr 123:583-585

9. Chang MH, Hsu HY, Ni YH, Tsai KS, Lee PI, Chen PJ, Hsu YL, Chen DS 1998 Precore stop codon mutant in chronic hepatitis B virus infection in children: its relation to hepatitis $\mathrm{B}$ e seroconversion and maternal hepatitis B surface antigen. J Hepatol 28:915-922

10. Okamoto H, Tsuda F, Akahane Y, Sugai Y, Yoshiba M, Moriyama K, Tanaka T, Miyakawa Y, Mayumi M 1994 Hepatitis B virus with mutations in the core promoter for an e antigen-negative phenotype in carriers with antibody to e antigen. J Virol 68:8102-8110

11. Yuh CH, Chang YL, Ting LP 1992 Transcriptional regulation of precore and pregenomic RNAs of hepatitis B virus. J Virol 66:4073-4084

12. Moriyama K, Okamoto H, Tsuda F, Mayumi M 1996 Reduced precore transcription and enhanced core-pregenomic transcription of hepatitis B virus DNA after replacement of the precore-core promoter with sequences associated with e antigenseronegative persistent infections. Virology 226:269-280

13. Buckwold VE, Xu Z, Chen M, Yen TS, Ou JH 1996 Effects of a naturally occurring mutation in the hepatitis B virus basal core promoter on precore gene expression and viral replication. J Virol 70:5845-5851

14. Barbera C, Calvo P, Coscia A, Perugini L, Dastoli G, Randone A, Bonino F, Brunetto MR 1994 Precore mutant hepatitis B virus and outcome of chronic infection and hepatitis in hepatitis B e antigen-positive children. Pediatr Res 36:347-350

15. Friedt M, Gerner P, Lausch E, Trübel H, Zabel B, Wirth S 1999 Mutations in the basic core promoter and the precore region of hepatitis $\mathrm{B}$ virus and their selection in children with fulminant and chronic hepatitis B. Hepatology 29:1252-1258

16. Hsu HY, Chang MH, Lee CY, Hsieh KH, Ni YH, Chen PJ, Chen DS 1995 Precore mutant of hepatitis B virus in childhood fulminant hepatitis B: an infrequent association. J Infect Dis 71:776-781

17. Kwok S, Higuchi S 1989 Avoiding the false positive with PCR. Nature 339:237-238

18. Naito H, Hayashi S, Abe K 2001 Rapid and specific genotyping system for hepatitis $\mathrm{B}$ virus corresponding to six major genotypes by PCR using type-specific primers. J Clin Microbiol 39:362-364

19. Lindh M, Anderson AS, Gusdal A 1997 Genotypes, nt 1858 variants, and geographic origin of hepatitis B virus-large scale analysis using a new genotyping method. J Infect Dis 175:1285-1293

20. Honda A, Yokosuka O, Ehata T, Tagawa M, Imazeki F, Saisho H 1999 Detection of mutations in the enhancer 2 /core promoter region of hepatitis B virus in patients with chronic hepatitis B virus infection: comparison with mutations in precore and core region in relation to clinical status. J Med Virol 57:337-344

21. Yuen MF, Sablon E, Yuan HJ, Wong DK, Hui CK, Wong BC, Chan AO, Lai CL 2003 Significance of hepatitis B genotype in acute exacerbation, HBeAg seroconversion, cirrhosis-related complications, and hepatocellular carcinoma. Hepatology 37:562-567

22. Parekh S, Zoulim F, Ahn SH, Tsai A, Li J, Kawai S, Khan N, Trépo C, Wands J, Tong S 2003 Genome replication, virion secretion, and e antigen expression of naturally occurring hepatitis B virus core promoter mutants. J Virol 77:6601-6612

23. Günther S, Piwon N, Iwanska A, Schilling R, Meisel H, Will H 1996 Type, prevalence, and significance of core promoter/enhancer II mutations in hepatitis B virus from immunosuppressed patients with severe liver disease. J Virol 70:8318 8331

24. Kidd-Ljunggren K, Öberg M, Kidd AH 1997 Hepatitis B virus X gene 1751 to 1764 mutations: implications for HBeAg status and disease. J Gen Virol 78:1469-1478

25. Kao JH, Chen PJ, Lai MY, Chen DS 2000 Hepatitis B genotypes correlate with clinical outcomes in patients with chronic hepatitis B. Gastroenterology 118:554-559

26. Chan HL, Hussain M, Lok AS 1999 Different hepatitis B virus genotypes are associated with different mutations in the core promoter and precore region during hepatitis B e antigen seroconversion. Hepatology 29:976-984 